EGU21-13197

https://doi.org/10.5194/egusphere-egu21-13197

EGU General Assembly 2021

(c) Author(s) 2022. This work is distributed under

the Creative Commons Attribution 4.0 License.

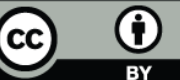

\title{
The representativeness of ground-based air quality monitoring stations: observation and recommendation from Indian cities
}

\author{
Arindam Roy ${ }^{1}$, Satoshi Takahama ${ }^{1}$, Athanasios Nenes ${ }^{2,3}$, Sumit Sharma ${ }^{4}$, and Anju Goel ${ }^{4}$ \\ ${ }^{1}$ ENAC/IIE Swiss Federal Institute of Technology Lausanne (EPFL), 1015 Lausanne, Switzerland (arindam.roy@epfl.ch) \\ ${ }^{2}$ School of Architecture, Civil and Environmental Engineering, Swiss Federal Institute of Technology Lausanne, Lausanne \\ 1015, Switzerland \\ ${ }^{3}$ Institute of Chemical Engineering Sciences, Foundation for Research \& Technology-Hellas, Patras 26504, Greece \\ ${ }^{4}$ Earth Science and Climate Change Division, The Energy and Resource Institute, Delhi, India
}

It is well established that the high level of particulate matter is a leading cause of premature mortality and disease worldwide and especially in South Asia (Global Burden of Disease Study, 2019). The ground-based air quality (AQ) monitoring stations are used to calculate economic loss, premature mortality and validate the conversed PM2.5 concentration from satellite-based Aerosol Optical Depth (AOD) data. Over India, 793 manual monitoring air quality (AQ) monitoring stations and 307 automated AQ monitoring station are presently operating under the aegis of National Air Quality Monitoring Programme and Central Pollution Control Board respectively. However, studies addressing the spatial representativeness of the data generated from the AQ monitoring stations over India are very limited and therefore, it is unclear that whether the existing stations are sufficient to reflect the average ambient AQ over different Indian cities.

The present study intends to classify the existing AQ monitoring stations on the basis of spatial representativeness and derive a general conceptual framework for commissioning representative AQ monitoring sites for Indian cities. The methodology involves analysis of land use, populations and air quality data for the existing air quality stations in million plus Indian cities. A case study was conducted for Pune $\left(18.5^{\circ} \mathrm{N}, 73.8^{\circ} \mathrm{E}\right)$, a western Indian metro city with 3.15 million population (Census, 2011). Using the night-time light data and high resolution PM2.5, population exposure hotspots over Pune city were identified. It was observed that not only at the midst of the municipal area, population exposure hotspots can be identified at the peripheral region of PMC/PNMC which certainly signify the role of rapid developmental activity and urban agglomeration over Pune city. The existing air quality monitoring sites are located majorly in the pollution hotspots in the city center region and therefore installing AQ monitoring stations (co-located with weather station) at the rapidly developing parts of the city is highly recommended. The present land use pattern and the location of existing monitoring sites suggests lack of urban background monitoring stations which indicates the gap of knowledge in monitoring the average air quality responsible of longterm health effect over Pune. The prevalence of AQ monitoring stations in the road junction points 
and near to metro construction works might overestimate the exposure estimate of the general population in the city. 